\title{
Review
}

\section{Health Technology Assessment (HTA) and health policy making: a narrative review}

\author{
Anuji Upekshika Gamage ${ }^{1 *} \&$ Chrishantha Abeysena ${ }^{2}$ \\ ${ }^{1}$ Faculty of Medicine, General Sir John Kotelawala Defence University, Sri Lanka; ${ }^{2}$ Department of Public Health, \\ Faculty of Medicine, University of Kelaniya, Sri Lanka
}

*Correspondence: anujigamage@gmail.com D iDttps://orcid.org/0000-0002-4713-9283

DOI: https://doi.org/10.4038/jccpsl.v26i3.8271

Received on 25 February 2020

Accepted on 17 June 2020

\begin{abstract}
Introduction: Health Technology Assessment (HTA) is a policy tool for informed decision making that supports the entry and use of health-technologies. Three main forces have driven the development of HTA; rising healthcare demands and expectations, scarcity of resources, and increasing entry of new technologies to the healthcare market. With a commitment to Universal Health Coverage (UHC), decisions on allocations considering cost-effectiveness is crucial.
\end{abstract}

Objectives: To evaluate the global evidence on the process, outcome and importance of HTA and evidence-based decision making in health policymaking and the potential way forward in Sri Lanka

Methods: A narrative review on HTA and policy making was undertaken using the databases Medline, Embase, Biomedcentral, Science Direct, Web of Science. Useful websites, reports were looked up. The search was conducted during JulyDecember 2019. The search strategy for scientific literature consisted of free text and MeSH terms related to keywords, namely, HTA, evidence-informed decision making, HTA-report and health policy. For the SWOT analysis and the way forward, literature review and expert opinion were obtained.

Results: HTA studies the medical, social, ethical, and economic implications of development and use of health-technology and guides the healthcare system in evidence-based decision making that is patient-centred and achieves the highest value for money. Once the topic nomination and prioritization of health-technology is done, it undergoes assessment, appraisal and decision making. Most countries have a process of collecting and analysing information about health technologies mainly for planning and budgeting purposes and most reports mainly on safety and clinical effectiveness, followed by economic and budgetary considerations. The findings generated through the HTA-process were used mainly to inform decision makers in most countries.

Implementation of HTA needs the following; 1. A competent health information technology infrastructure, 2. Establish a core HTA team and building national capacity 3. Transparency of HTA agency and process and legislations 4. Extensive networks 5. Linking HTA to decision making the process.

Conclusions: HTA is an essential tool for evidence-based decision making and allocating health budgets towards achieving UHC. HTA systematically evaluates the effectiveness, costs, and health impact, of a health-technology while considering ethical and equity issues. Institutionalizing HTA needs a conducive environment and commitment.

Keywords: HTA, evidence-informed decision making, health policy, institutionalizing HTA 


\section{Introduction}

Rapidly rising healthcare expenditure is a growing concern globally. As an effort to keep pace with the latest health technologies and implementing propoor reforms to advance universal health coverage, countries employ varying approaches to provide affordable quality access to healthcare. Health Technology Assessment (HTA) is widely used as an approach to allocating healthcare resources. HTA is a form of policy research that systematically examines the short and long term consequences of health technology, a set of related technologies, or technology-related issues (1-2), which helps decision-makers to make a better decision. Health technology is an intervention that may be used to promote health, to prevent, diagnose, or treat acute or chronic disease, or for rehabilitation. Health technologies include pharmaceuticals, devices, procedures, and organizational systems used in health care (3). Examples include prevention programs (i.e. vaccination), diagnostic tests (i.e. mammography), a device or piece of equipment (i.e. stents used in coronary artery bypass grafting), a drug (i.e. the use of rapid-acting insulin analogues in patients with diabetes mellitus type 1) and a procedure (i.e. laparoscopy). HTA is a multidisciplinary field of analysis that examines the medical, economic, social, and ethical implications of the incremental value, diffusion, and use of medical technology in health care (Figure 1). HTA interprets and synthesis evidence from the research findings and determines how these results could be applied to the local health context and therefore is useful in informed decision making(2).

The financing for the healthcare system in Sri Lanka consists mainly of general taxation and out of pocket payments from households -(4-5). With rapidly changing epidemiological and demographic patterns and the challenges of facing emerging and reemerging diseases, it is timely to consider the current financing mechanisms and decisions for allocations of health resources at both national and provincial levels. Failing to address this would lead to inefficient service deliveries and increase out of pocket expenditure (6-7). Although currently, HTA is not used in the decision-making process in Sri Lanka with a commitment to Universal Health Coverage (UHC) decisions on investments considering costeffectiveness is crucial. This paper aims to discuss the documented global evidence on the importance and the relationship between HTA and evidence-based decision making in health policymaking, the process, and methodology of HTA and the potential way forward in Sri Lanka.

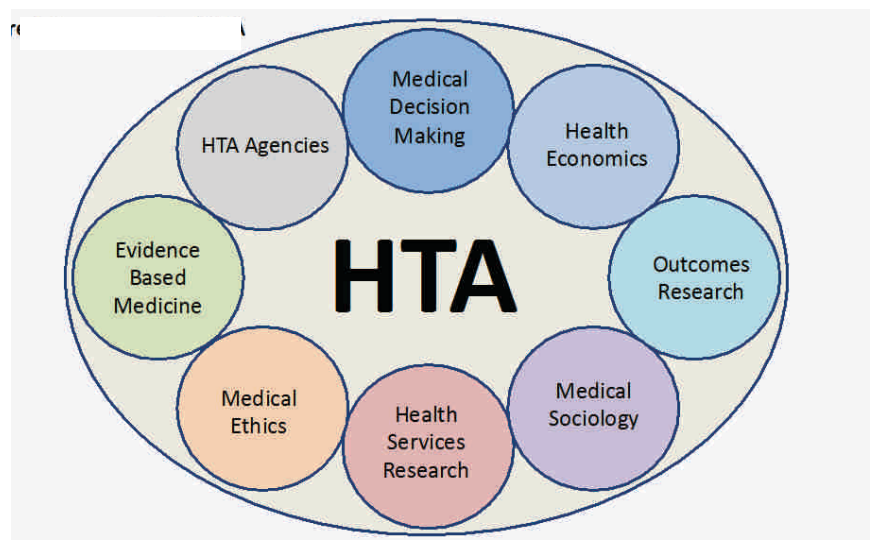

Figure 1: Components of HTA

\section{Methods}

A narrative review on HTA, HTA agencies, HTA and policymaking was undertaken using the databases, Medline, Embase, Biomed Central, Science Direct, Web of Science and Cochrane Reviews for relevant articles. Also, useful websites and reports were looked up. The search was conducted during JulyDecember 2019. The search strategy for scientific literature consisted of free text and MeSH terms related to the following keywords: 'health technology assessment, evidence-based decision making and institutionalising health technology assessment. The resulting hits were filtered for the term "South Asian countries." Systematic reports and other reviews as well as research findings were considered. The references of retrieved articles were manually searched for further material.

Citation information, along with notes and abstracts were downloaded to Endnote X9 software. For the Strengths, Opportunities, Weaknesses, and Threats analysis (SWOT) Literature review and expert opinions from the fields of Community Medicine, Medical Administration and Economics were used. The primary purpose of the search was to generate evidence HTA as a necessary tool in the healthcare 
decision-making process for setting priorities in Sri Lanka.

\section{Why do we need HTA in Sri Lanka?}

Health systems everywhere in the world are under pressure due to unlimited user expectations and goals to achieve in the context of finite budgets and limited/ resources. Hence, the burden of healthcare systems to change has also been mounting. As such, countries have been exploring ways to transform their healthcare systems in recent years, while many developing countries are working to improve their health systems (7).

\section{The HTA work process}

As with any research, the HTA too starts with a policy question. The policy question could be related to a new/existing technology, a new project, or a best practice (clinical, economical, socially), etc. For example, a policy question related to technology would look at 1 . What is the place for technology? 2. What technology would it replace? 3. Who will use the technology? 4. What would be the impact of the introduction of the new technology? The policy question is then converted to an HTA research question which would look at the populations being targeted with the technology (Population), what technology is being considered (Interventions), what is currently being done (Comparators), and outcomes that are most relevant to determine safety, effectiveness, and cost-effectiveness (Outcomes). Hence, these are considered as the PICO criteria of HTA.

The work process of HTA usually consists of the following by three phases (Figure 2): 1. Assessment: collation and critical review of scientific evidence together with compilation and formulation of findings 2. Appraisal: evaluation of the compiled findings while considering all other factors (financial resources priorities for health services in the country and/or the health needs of the community) by a committee to make a recommendation whether or not to finance the new technology 3. Decision-making: implementation of suitable technologies and together with monitoring and evaluation.

HTA is a multi-disciplinary task. The main disciplines are clinical medicine (this depends on the context), epidemiology (systematic reviews and metaanalysis), health economics, statistics and ethical consideration. HTA may look at the impact of technology on an individual patient, on a group of similar patients, on the healthcare system as a whole, or all of these. HTA may assess evidence from a range of sources, for example systematic reviews of clinical trials; economic evaluations; assessments of implications for healthcare services; and evidence from users of the technology (3). Decisions should be on par with recommendations made in the HTA report. If not, clear justification should be made available as to why there are differences in the decisions that were taken. The decision making body is ideally the individuals or institutions/ responsible authority in the provision of healthcare (2), i.e., the Ministry of Health in Sri Lanka. However, this body should be an independent entity of the HTA assessing body; to allow better decision making in accordance with the first decision maker's objectives and second reasonable understanding of evidence. HTA helps a decision-maker in making a balanced and fair decision.

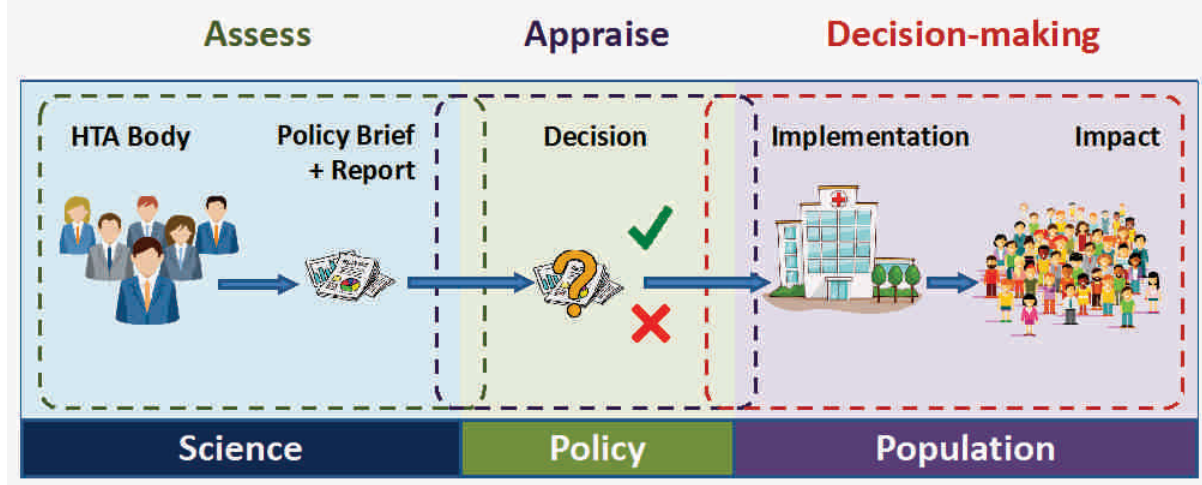

Source: www.eupati.eu Figure 2: The process of Health Technology Assessment (HTA) evidence informed decision making 


\section{The outcome of an HTA process}

HTA is a decision-making tool that allows important distinctions to be made. HTA explores the alternative interventions for a defined condition. The assessment should include the following; evidence on the technology, an economic analysis of the technology/ the approach to any synthesis and extrapolation of results from the literature, medico-legal implications and considerations, considerations of societal social consequences and a detail ethical consideration, and finally a statement on the consequences of the assessment results and conclusions. As such, an HTA provides $\mathrm{s}$ logical framework embodying two elements, namely science-based element and valueladen element. The value-laden component provides social value judgments to be made, including fairness, perspective and preferences.

\section{Global evidence on HTA}

\section{History}

The first report on the development of HTA originates from the US Office of Technology Assessment (OTA), which was published in 1976, mainly focusing on efficacy and safety (9). Thereafter, HTA has spread to nearly all European countries, Australia, Latin America and Asia (9-10). The expansion prompted many of those working in HTA to initiate societies /network of people interested in HTA. A few established HTA and related organizations are ISTAHC and HTAi, INAHTA, EuroScan, WHO, World Bank, PAHO, Cochrane collaboration. Over the last thirty years, HTA has flourished (11), and its noteworthy to mention that in Asia, the first HTA body to be established was the Malaysian Health Technology Assessment section (MaHTAS) (12).

\section{International HTA Agencies and tasks}

There is a global effort to achieve universal health coverage (UHC), and in this, the process of deciding which health technologies and interventions to invest in has become increasingly important over the years. Global Survey on Health Technology Assessment by National Authorities (13) studied 111 countries consisting of HTA bodies. It reports that most countries had a formal process to support health care policy decision making. All low-income countries and $84 \%$ of the middle-income countries utilized HTA information for planning and budgeting. Highincome countries used HTA to determine reimbursement or in the design of the benefits package (13). Eighty-five percent of the middleincome countries utilized HTA to inform clinical practice guidelines and protocols. The majority of the countries studied reported that the HTA agency consisted of about six staff members, who are mainly public health and clinical science professionals, and exploring public health involvement is a growing concern $(11,13)$. Most HTA agencies have no or do not involve in the decision-making process, but provide evidence to support the decision. In contrast to this National Institute for Health care Excellence (NICE) of the UK, which is the most influential HTA agency, it is also involved in the decision-making process (12).

Considering Asia, the policy brief on "Factors conducive to the development of HTA in Asia" reports of HTA agencies in Malaysia, Korea, Thailand, China, Indonesia, and Vietnam (12). The majority of these countries function with a low gross domestic product on health and limited fiscal space to expand (12), hence are under pressure to prioritize healthcare delivery while meeting demands for healthcare services. The HTA agencies in these countries assess technologies related to medicines, devices and public health interventions. They are also involved in research for evidence. The number of HTA projects conducted per year varies from country to country. It is reported that Malaysia and Korea have well established HTA bodies, which are autonomous and highly independent political pressure and play a vital role in evidence-informed policy development and decisions $(12,14-15)$.

\section{Health Technology Assessment in Sri Lanka}

Successful implementation of HTA needs the following: 1. A competent health information technology infrastructure, 2. Establish a core HTA team and building national capacity 3 . Transparency of HTA agency and process and legislations 4 . 
Extensive networks 5. Linking HTA to the decision making process.

Healthcare in Sri Lanka is provided through the public and private sectors. The Ministry of Health Sri Lanka is responsible for comprehensive health care provision throughout the country. The present system was established in 1989. Three levels of health care are identified, which comprise a decentralized pyramidal system (curative, preventive and rehabilitative). At the central level, the Director General of Health Services (DGHS) is responsible for the technical aspects of health care services . Being a developing country, most of the health facilities in Sri Lanka are supplied by the government sector free of charge funded by taxes. According to the National Health Accounts, government health care expenditure in 2016 was $3.9 \%$ of GDP.

Sri Lanka is a lower-middle-income country. Although, over the years, most of the indicators show that many diseases have been controlled, resulting in substantially declined morbidity and mortality. In all countries of the world, increasing pressures on scarce resources have meant that all investments as well as the health sector, have come under closer scrutiny. As an upper-middle-income country with scarce resources, lack of financial resources magnifies the need for health care while shrinking the capacity to finance it . Hence, health financing and decisionmaking must be evidence-based to gain maximum output from minimal input while at the same time maintaining its equity and efficiency.

Efficiency and equity are two essential concepts in any healthcare system. Efficiency in health can be defined as obtaining most out of scarce resources. Efficiency is attained when the community's wellbeing is maximized, given the resources available. It emphasizes minimal waste of resources, production of outputs at the least cost, and produces the types and quantity of output that people value most. Health services try to maximize health gains and the efficiency of scarce resources. Three types of efficiencies are discussed, and they are technical, allocative, and cost-effective efficiency. With regards to efficiency, there is Pareto Efficiency, a concept originating from welfare economics and states that it is not possible to change the allocation of resources to make any one person better off without making at least one other person worst off. Equity in healthcare can be defined as the absence of systematic differences between health between social groups who have different levels of social advantages /disadvantages. For any healthcare system to be successfully providing the healthcare needs of a population, efficiency and equity are two necessary components. The Sri Lankan healthcare system aims at providing efficient and equitable services and hence continuously seeks ways to improve the existing system.

\section{Cost-effectiveness, HTA and ICER threshold}

In cost-effectiveness analysis, the funding decisions are mainly based on its output, which is the CostEffective Incremental Ratio (ICER). The ICER is defined as a summary measure representing the economic value of an intervention compared with an alternative (comparator). The ratio depicts the 'extra cost per extra unit of health effect.' The ICERS are compared with a ceiling ratio, which is the ICER threshold () in the cost-effectiveness decision making as this guides in the efficient use of scarce resources. ICER threshold () is defined as 'the maximum amount a decision-maker is willing to pay for a unit of health outcome' and is closely related to the concept 'opportunity cost'. Some countries like England, Wales and Australia have explicit thresholds, while most countries in the SEARO do not have specific thresholds. In such countries, silo-based decision making without adequate consideration of evidence and lack of transparency is seen. The WHO defines that the ICER threshold () for SEARO countries is three times the GDP per capita per DALY averted. Highly cost-effective interventions are defined as meeting a threshold per DALY averted of once the annual GDP per capita. However, it should also be noted that ICER is not the only decision-making criterion, as other critical decision-making and prioritization factors are usually relevant and that various countries adopt various techniques to find healthcare programs (. Considering the three times the GDP per capita per DALY averted information, the ICER threshold () for Sri Lanka is (GDP per capita in Sri Lanka in 2019 amounted to around 3853 U.S. 
dollars) 11559 (U.S. dollars) per capita per DALY averted.

\section{HTA and Cochrane reviews}

As mentioned, afore, the HTA report consists of many components, such as effectiveness, safety, costeffectiveness, ethical aspects, etc. To obtain the evidence for each component and to obtain information on existing and ongoing HTA, systematic searches are conducted. Cochrane database is one such source for evidence as it consists of synthesized systematic reviews of primary research related to healthcare and policy. Cochrane is useful in many aspects as it could provide reviews of process evaluation, effectiveness, implementation strategies, and acceptability. The Cochrane systematic reviews are prepared and supervised by a Cochrane Review team and attempt to identify, appraise and synthesize all the empirical evidence that meets pre-defined eligibility criteria to answer a specific research question. Once the scope and the research question is decided, the searches are carried out by a network of researchers, professionals, patients, carers, and people interested in health .
Therefore, Cochrane provides a platform to find useful evidence. Linking research findings to inform policy decisions in healthcare is the relationship between Cochrane and HTA.

\section{Situation analysis in Sri Lanka}

Although HTA is a necessary tool for setting priorities, it is not yet established in Sri Lanka. Owing to the changing demographics and epidemiological situation, healthcare expenditure in Sri Lanka is facing a rapid increase. Irrational resource allocation processes would impede the achievement of UHC efficiency, effectiveness including cost-effectiveness, and other important technical criteria are over-looked. However, similar to other countries, components of HTA are practised in bodies, such as the National Medicines Regulatory Authority (NMRA) that plays a leading role in assessing the need, while ensuring safety, quality and efficacy in medicinal products available in the country. The barriers in HTA development at the country level identified in the policy brief do exist in Sri Lanka too. As shown in Table 1, a SWOT analysis was conducted based on literature review and expert opinion.

\section{Table 1: SWOT analysis for the implementation of HTA in Sri Lanka}

\begin{tabular}{|c|c|}
\hline Strengths & Weaknesses \\
\hline $\begin{array}{l}\text { Trained human resources for the components of } \\
\text { HTA }\end{array}$ & $\begin{array}{l}\text { Lack of collective decision making/ silo -based } \\
\text { decision making / Lack of stakeholder involvement }\end{array}$ \\
\hline Place for Evidence based decision making & Lack of good quality/ comprehensive data \\
\hline Technical and Funding agencies who are interested & Provider induced demand \\
\hline National Policy on Health & Lack of a single decision -making body \\
\hline Need for improvement of efficacy & Possible resistance from the internal environment \\
\hline \multicolumn{2}{|l|}{$\begin{array}{l}\text { National Medicines Regulatory Authority (NMRA) } \\
\text { and the Medicines Evaluation Committee (MEC) }\end{array}$} \\
\hline Opportunities & Threats \\
\hline Health is a priority sector & Demand for new and better technologies \\
\hline \multicolumn{2}{|l|}{ Demand for transparent decision making } \\
\hline Healthcare reforms (Health financing reform) & Attitudes and opinions towards HTA \\
\hline Growing attention in healthcare decision making & Research funding and dissemination \\
\hline Legal issues related to health and safety & Market monopoly \\
\hline
\end{tabular}




\section{Conclusion}

- HTA is a useful tool for policymakers and decision-makers to assess the value of a range of health technologies, which would help in maximizing the impact of finite healthcare budgets and improve efficiency. Importantly it assists in consideration of efficiency, effectiveness, and fairness in decision making.

- It was found that most countries have a process of collecting and analysing information about health technologies mainly for planning and budgeting purposes. Findings generated through the HTAprocess were used mainly to inform decision makers in most countries.

- HTA is a mechanism to introduce a value for money in the healthcare system, and the adoption of HTA should be considered in developing countries, given the increase in demand in quality healthcare.

- It was also reported that in most countries they focused mainly on safety and clinical effectiveness, followed by economic and budgetary considerations. However, it was reported that little consideration was given to ethics, equity and applicability of the technology.

- Countries starting in HTA, such as ours, should not wait for 'full' capacity to do HTA, as decisions still need to be made for the most efficient allocation of scarce health resources. HTA can aid in the development of better information systems over time. In the longer term, health systems can work to address data gaps and harness the power of existing, routinely collected health services data.

- Stakeholder involvement in the HTA process is, and the stakeholder should identify the basic principles underlying HTA, to contribute effectively in the decision-making process.

- Traditional expert-based decision making should be replaced by more transparent, evidence-based decision making by the implementation of the HTA institution.

\section{References}

1. NIH. Introduction to Health Technology Assessment USA, 2019. Available from: https:// www.nlm.nih.gov/nichsr/hta101/ta10103.html.

2. Culyer AJ. Health economics and health technology assessment. Medicine 2018; 46(7): 379-382.

3. INHTA. HTA tools \& resources, 2020. Avaialble from: http://www.inahta.org/hta-tools-resources/.

4. Amarasinghe SN, Dalpatadu KCS, Rannan-Eliya RP. Sri Lanka health accounts: national health expenditure 1990-2016. Health Expenditure Series, vol. 5. Colombo: Institute for Health Policy, 2018.

5. Ministry of Health. Sri Lanka national health accounts 2014-2016. Colombo: Ministry of Health, Sri Lanka, 2018.

6. Samarage DSM. Health Care System Sri Lanka. Migration and human resources for health: from awareness to action. ILO/IOM/WHO, Geneva, 2324 March, 2006.

7. Smith O. Achieving Pro-poor universal health coverage without health financing reforms. Universal Health Coverage Study Series No 38. Washington DC: World Bank, 2018.

8. Busse R, Orvain J, Velasco M, Perleth M, Drummond M, G“rtner F, Jørgensen T, Jovell A, Malone J, R"ther A et al. Best practice in undertaking and reporting Health Technology Assessments. Working Group 4 Report. International Journal of Technology Assessment in Health Care 2002; 18(2): 361-422.

9. Chootipongchaivat S, Tritasavit N, Luz A, Teerawattananon Y, Tantivess S. Conducive factors to the development of Health Technology Assessment in Asia. Policy Brief and Working Report 2016. Available from: https://doi.org/ 10.7490/f1000research.1113910.1.

10. Fernando D. Health care systems in transition III Sri Lanka, Part I. An overveiw of Sri Lanka's health care system. Journal of Public Health Medicine 2000; 22(1): 14-20.

11. Medical Statistics Unit. Annual Health Bulletine. Colombo: Ministry of Health, Sri Lanka, 2013.

12. WHO. Health systems financing: the path to universal coverage. World Health Report. Geneva: World Health Organization, 2010. 
13. Boadway RF \& Bruce N. Welfare Economics. Oxford: Basil Blackwell, 1984.

14. York Health Economics Consortium. Incremental Cost-Effectiveness Ratio (ICER). York, 2016. Available from: https://yhec.co.uk/glossary/ incremental-cost-effectiveness-ratio-icer/.

15. York Health Economics Consortium. CostEffectiveness Threshold. York, 2016. Available from https://yhec.co.uk/glossary/costeffectiveness-threshold/

16. Chootipongchaivat S T, Luz A, Teerawattananon, Tantivees S. Factors conducive to the development of health technology assessment in Asia. Impacts and policy options. Manila: World Health Organization, Regional Office for the Western Pacific, 2015.

17. Marseille E, Larson B, Kazi DS, Kahn JG, Rosen S. Thresholds for the cost-effectiveness of interventions: alternative approaches. Bulletin of the World Health Organization 2015; 93(2): 118124.

18. Shillcutt SD, Walker DG, Goodman CA, Mills AJ. Cost effectiveness in low- and middle-income countries: a review of the debates surrounding decision rules. PharmacoEconomics 2009; 27(11): 903-917.

19. Evans DB, Lim SS, Adam T, Edejer TT-T, WHO Choosing Interventions that are Cost Effective (CHOICE) Millennium Development Goals Team. Evaluation of current strategies and future priorities for improving health in developing countries. $B M J$ 2005;331(7530): 1457-1461.

20. Jadad AR \& Haynes RB. The Cochrane Collaboration--advances and challenges in improving evidence-based decision making. Medical Decision Making 1998; 18(1): 2-9; discussion 16-18.

21 Higgins JPT, Thomas J, Chandler J, Cumpston M, Li T, Page MJ, Welch VA. Cochrane Handbook for Systematic Reviews of Interventions. Chapter 2: determining the scope of the review and the questions it will address, 2019.

22. National Medicines Regulatory Authority (NMRA). Resitration and regulation information. 2020. Available from: https://nmra.gov.lk/i ndex.php?option $=$ com_content $\&$ view $=$ article $\&$ id $=90 \&$ Itemid $=168 \&$ lang $=$ en. 